\title{
O BURNOUT ENTRE PROFESSORES EM AJUSTAMENTO FUNCIONAL NA ESCOLA PÚBLICA ESTADUAL CURVELO/MINAS GERAIS
}

\author{
THE BURNOUT BETWEEN TEACHERS IN FUNCTIONAL ADJUSTMENT IN \\ THE CURVELO / MINAS GERAIS STATE PUBLIC SCHOOL
}

\author{
Tânia Aparecida Leite Ferreira ${ }^{1}$ \\ Brenda Maria Leite Ferreira ${ }^{2}$
}

RESUMO. Este estudo busca responder a seguinte questão: a Síndrome de Burnout é a principal responsável pelos casos de ajustamento funcional de professores? Tem-se como objetivo geral analisar o grau de incidência da Síndrome de Burnout para os casos de afastamentos funcionais de professores na Escola Estadual Ministro Adauto Lúcio Cardoso, na cidade de Curvelo/MG. Nesse sentido, o objetivo geral desta pesquisa é investigar o grau de incidência da Síndrome de Burnout em professores da Escola Estadual Ministro Adauto Lúcio Cardoso, em Curvelo-MG, a partir da análise dos casos de afastamentos funcionais e como objetivos específicos apresentar uma abordagem teórica sobre a Síndrome de Burnout e a profissão docente; associar os fatores descritos na literatura como possíveis causas da Síndrome de Burnout em professores; descrever as estratégias que foram usadas para evitar a Síndrome entre os professores; verificar as ações realizadas na instituição no processo de ajustamento funcional dos professores.

Palavras-chave: Síndrome de Burnout. Ajustamento funcional. Professor.

ABSTRACT: This study aims to answer the following question: is Burnout Syndrome the main responsible for the cases of functional adjustment of teachers? The objective of this study is to analyze the degree of incidence of Burnout Syndrome in the cases of functional departures from teachers at the State School Ministro Adauto Lúcio Cardoso, in the city of Curvelo / MG. In this sense, the general objective of this research is to investigate the degree of incidence of Burnout Syndrome in teachers of the State School Minister Adauto Lúcio Cardoso, in Curvelo-MG, from the analysis of the cases of functional distances and as specific objectives to present a theoretical approach on Burnout Syndrome and the teaching profession; to associate the factors described in the literature as possible causes of Burnout Syndrome in teachers; describe the strategies that were used to prevent Syndrome among teachers; verify the actions taken in the institution in the process of functional adjustment of teachers.

Keywords: Burnout syndrome. Functional adjustment. Teacher.

\footnotetext{
${ }^{1}$ Graduada em Ciências Humanas pela Faculdade de Ciências Humanas de Curvelo/Extensão UFM. Professora de Física na Rede Pública de Ensino do Estado de Minas Gerais. Pós- graduada em Metodologia da Matemática - Faculdade São Luís - Jaboticabal/SP. Mestre em Ciências da Educação pela Universidade Autônoma de Assunção.

2 Graduanda em Medicina pela Universidade Federal do Triângulo Mineiro. Coordenadora de Extensão da Liga de Emergências Clínicas. Monitora Concursada na disciplina "Semiologia" do Curso de Graduação em Medicina na Universidade Federal do Triângulo Mineiro - UFTM.
} 


\section{INTRODUÇÃO}

Atuar de forma assertiva como professor, educador e profissional da educação tem se tornado cada vez mais difícil, uma vez que tantos conflitos se convergem no cotidiano da sala de aula. Conflitos com a política pública vigente de remuneração, pressão por resultados na aprendizagem, exigência de cumprir o currículo, salas lotadas, infra-estrutura inadequada, falta de motivação para aprender e, também, para ensinar, relacionamentos interpessoais fragilizados, falta de assistência, de modo geral, os profissionais da educação se tornam potencializadores de estresse no desempenho da função. Portanto, para entender e verificar o que vem provocando tantos afastamentos de professores da sala de aula é que despertou o interesse em pesquisar esse tema.

A síndrome de Burnout é um fenômeno psicossocial relacionado diretamente à situação laboral. A síndrome, definida por Maslach (198I) como uma reação à tensão emocional crônica, que afeta de forma negativa os profissionais e suas relações com o trabalho, proporcionando desgaste emocional, estresse e em alguns casos na desistência do indivíduo de trabalhar ou em caso mais grave de viver.

Em docentes, a síndrome se evidência por uma exaustão dos recursos emocionais próprios, em que são comuns atitudes negativas e de distanciamento para com os alunos e a valorização negativa de seu papel profissional. É uma síndrome através da qual o sujeito perde o sentido da sua relação com o trabalho, de forma que as coisas já não importam mais. $O$ Burnout do professor poderia ser consideravelmente reduzido se nos cursos de formação de professores o assunto fosse abordado e técnicas de enfrentamento de estresse e Burnout fossem ensinadas e treinadas. Estando o professor ciente desse risco, ele teria melhores condições de reconhecer quando estivesse chegando aos seus próprios limites e adotaria as estratégias apropriadas.

Diante desse contexto, partindo da observação do ambiente de trabalho em escolas na cidade de Curvelo/ Minas Gerais, buscou-e investigar a seguinte tese: qual a incidência da Síndrome de Burnout nos casos de ajustamento funcional de professores na Escola Estadual Ministro Adauto Lúcio Cardoso em Curvelo/MG? 
Acredita-se que a Síndrome de Burnout influência nos casos de ajustamento funcional de professores apresentando sintomas que afetam as atividades diárias do educador gerando assim, um quadro de angustia quando se deparam com o cansaço, fadiga, o que culmina em licença médica, afastamento, isolamento social, estresse e muitas vezes, até aposentadoria precoce. Portanto, esta pesquisa tem como importância alertar os professores para os sintomas e as causas do burnout, além de apresentar medidas preventivas para se evitar ou reduzir os eventos tensores causadores da Síndrome de Burnout.

Nesse sentido, tem-se como objetivo geral desta pesquisa analisar o grau de incidência da Síndrome de Burnout para os casos de afastamentos funcionais de professores na Escola Estadual Ministro Adauto Lúcio Cardoso, na cidade de Curvelo/MG e como objetivos específicos apresentar uma abordagem teórica sobre a Síndrome de Burnout e a profissão docente; associar os fatores descritos na literatura como possíveis causas da Síndrome de Burnout em professores; descrever as estratégias que foram usadas para evitar a Síndrome entre os professores; verificar as ações realizadas na instituição no processo de ajustamento funcional dos professores.

O Burnout é uma síndrome multifatorial e parece resultar da conjugação de fatores internos (vulnerabilidades biológicas e psicológicas) e externos (o ambiente de trabalho). Esses fatores são percebidos e avaliados pelo professor à luz de suas atitudes, crenças e valores, de suas experiências passadas e de seu estilo de vida. Se forem interpretados negativamente, como uma ameaça à sua autoestima, e se os professores não dispõem de técnicas de enfrentamento eficientes, poderão levá-lo ao Burnout com seus sintomas típicos de exaustão física, emocional.

\section{REVISÃO DE LITERATURA SÍNDROME DE BURNOUT: A DOENÇA DO ESGOTAMENTO PROFISSIONAL}

O termo Burnout foi criado pelo psicanalista americano Herbert Freudenberger em 1974 para descrever o adoecimento que observou em si mesmo e em amigos. Segundo Varella (2013), Freudenberg definiu a referida síndrome como "um estado de esgotamento físico e mental cuja causa está intimamente ligada à vida profissional". E acrescenta, dizendo que o psicanalista americano constatou-a em si próprio em 1974, quando passa a ser conhecida como síndrome de esgotamento 
profissional ou pelo termo Burnout, que no inglês se traduz como queimar por completo; trata-se de um "incêndio interno"e resultante da tensão produzida pela vida moderna, afetando negativamente a relação subjetiva com o trabalho, afirma Jbelli (2008).

Freudenberg (1974) usou esta expressão para se referir a uma situação cada vez mais comum entre os trabalhadores e serviços humanos foi o fato de que, depois de meses ou anos de dedicação, estes trabalhadores tinham apenas queima. Assim, "O mercado de trabalho, cada vez mais exigente e competitivo, mantém algumas funções que expõem trabalhadores a situações de risco constante. Esse é o pano de fundo para o desenvolvimento do chamado mau estresse”. (Resk, 20II, p. 27).

A definição de "esgotamento" mais consolidado é a de Maslach e Jackson (198I) que a consideram uma resposta inadequada ao estresse crônico emocional, cujas principais características são: esgotamento físico e ou psicológico, uma atitude fria e despersonalizada em relação aos outros e um senso de inadequação às tarefas que tem de executar. A característica fundamental do "esgotamento" é a exaustão emocional ou o que é o mesmo, o sentimento de não ser capaz de dar mais de si mesmo a outros. Para se proteger de tal sentimento negativo, o assunto é isolado dos outros em desenvolvimento, portanto, um impessoal aos "clientes" membros atitude e de equipe, mostrando cínico, alienado, utilizando rótulos pejorativos para se referir a usuários ou tentar fazer culpados outros deixam cair suas frustrações e seu compromisso de trabalho.

Para Maslach et al (apud Vieira et al., 2006) a síndrome de Burnout é atribuída a estressores interpessoais crônicos no trabalho, que se caracteriza por exaustão emocional, despersonalização e diminuição da realização pessoal. $O$ contexto das relações sociais do trabalho docente é marcado por uma vivência profissional complexa.

Segundo Dias et al (2016), a sensação de estar acabado (Burnout) ou síndrome do esgotamento profissional é uma forma de resposta, que o organismo apresenta a estressores emocionais e interpessoais crônicos no trabalho. O profissional que, antes era muito envolvido com os alunos e com o seu trabalho, em si, desgasta-se e, em algum momento, desiste, perde o entusiasmo, a energia no que faz. O seu trabalho perde o sentido e qualquer esforço lhe parece inútil. 


\section{A SÍNDROME DE BURNOUT E A LEGISLAÇÃO BRASILEIRA}

Em 1943 foi aprovada a Consolidação das Leis do Trabalho (CLT), Decreto Lei $\mathrm{n}$ - 5.452, com o objetivo de unificar a legislação trabalhista existente no ordenamento jurídico brasileiro. No entanto, foi somente em 1988, com a atual Constituição Brasileira que os direitos trabalhistas se tornaram Princípios, direitos e Garantias fundamentais, Individuais e coletivos, dentre eles: jornada de trabalho de oito horas diárias e 44 horas semanais, direito a aviso prévio, décimo terceiro salário, afastamento remunerado, financiado pela Previdência social a partir do 16 o dia de afastamento, evitando a onerosidade do empregador.

No Decreto no 3048, de 6 de maio de 1999, que dispõe sobre a Regulamentação da Previdência Social, em seu Anexo II, que trata dos “Agentes Patogênicos causadores de Doenças Profissionais, conforme previsto no Art. 20 da Lei no 8. 213/9I", ao se referir aos transtornos mentais e do comportamento relacionados com o trabalho (presente no Grupo V da Classificação Internacional de Doenças - CID-ıo), no inciso XII aponta a "Sensação de Estar Acabado", "Síndrome de Burn-Out" ou "Síndrome do esgotamento Profissional", classificado como CID-ıo Z 73.o.

Segundo Menegol (2017), em face de a situação equiparada ao acidente de trabalho, o conceito surgiu, em um primeiro momento, através de jurisprudência e doutrina e foi inserida na Lei de Benefícios em momento posterior. $\mathrm{O}$ artigo 2I da Lei 8.213/91, determina a situação legalmente equiparada ao acidente de trabalho juntamente com o inciso I.

Art. 2I. Equiparam-se também ao acidente do trabalho, para efeitos desta Lei $[\ldots]$ :

I - o acidente ligado ao trabalho que, embora não tenha sido a causa única, haja contribuído diretamente para a morte do segurado, para redução ou perda da sua capacidade para o trabalho, ou produzido lesão que exija atenção médica para a sua recuperação. (Brasil, 2016, p. 07).

Isso quer dizer que, sempre que não houver uma causa direta ao meio ambiente de trabalho, mas de alguma forma, o empregador contribuiu para o agravamento de uma redução de incapacidade do empregado, perda ou até morte, seja por agressões, ofensas, disputas, imprudência, negligência, imperícia do empregador, contaminação acidental, ou até mesmo acidente fora do local d e trabalho, haverá o 
acidente do trabalho como causa, gerando consequentemente, os mesmo efeitos como se houvesse de fato o acidente de trabalho, afirma Menegol (2017).

\section{A SÍNDROME DE BURNOUT E O TRABALHO DOCENTE}

Ao longo da história, diversos acontecimentos marcam a vida do ser humano causando danos físicos e/ou mentais. Assim, o estresse não é um problema do século XXI. Todos os indivíduos, independentemente do sexo ou idade podem desenvolver o estresse. No entanto, o que interessa neste estudo é o estresse desenvolvido por causa da profissão, devido as características do trabalho que culminam no adoecimento psíquico e físico da pessoa.

O estresse característico do ambiente do trabalho é chamado de "estresse ocupacional" que, quando presente de forma mais prolongada tem sido designado como síndrome de Burnout. Nesse sentido, o Burnout é o resultado do estresse crônico que é típico do ambiente de trabalho, principalmente, quando nesse estão presentes situações de excessiva pressão, conflitos, poucas recompensas emocionais e pouco reconhecimento.

Segundo Carlotto (2011), as exigências e responsabilidades dos educadores tem aumentado bastante, coincidindo com o processo histórico de transformação rápida do contexto social, o que vem trazendo modificações no papel do professor no cotidiano da escola. Para a autora, essas mudanças estão ligadas a três fatores fundamentais. $\mathrm{O}$ primeiro diz respeito à evolução e transformação das famílias, que nos últimos anos, vem renunciando às suas responsabilidades no âmbito educativo, passando a exigir que as escolas assumam essa função.

O segundo fator está relacionado ao papel desempenhado pelas escolas que, tradicionalmente, representava a instituição responsável por transmitir o conhecimento, viu-se seriamente afetada pelo surgimento de novos agentes de socialização, que se converteram em fontes paralelas de informação e cultura. Já o terceiro fator está relacionado ao conflito que se instaura nas instituições quando se pretende definir qual é o papel do professor e quais valores, dentre os vigentes na sociedade, ele deverá transmitir e quais ele deverá questionar, afirma Carlotto (20II).

Os fatores apontados transformam-se em um profundo e exigente desafio pessoal para os professores que se propõem a responder às novas expectativas 
projetadas sobre eles. Nesse processo, os professores se deparam com a necessidade de desempenhar vários papéis, muitas vezes, contraditórios, que lhes exigem manter o equilíbrio em várias situações. É exigido do professor, ser amigo do aluno, apoiador do seu desenvolvimento pessoal e de sua autonomia; muitas vezes, é proposto que o professor atenda aos seus alunos individualmente e que siga as políticas educacionais, em outras, que o professor avalie e planeje conforme as necessidades dos alunos, porém em salas superlotadas.

Segundo França (2007), do ponto de vista público, o professor é extremamente cobrado em seus fracassos e raramente reconhecido por seu sucesso. Mesmo sendo uma tendência de várias profissões, a docência é a profissão que vem sendo severamente avaliada e cobrada pela sociedade em geral nas ultimas décadas.

Sendo assim, a Síndrome de Burnout entre os professores é um fenômeno complexo e multidimensional resultante da interação entre aspectos individuais, as atividades laborais e o ambiente de trabalho. Esse ambiente não é apenas restrito à sala de aula ou ao contexto escolar, mas sim a todos os fatores envolvidos nessa relação, incluindo os fatores macrossociais, como políticas educacionais.

\section{METODOLOGIA}

Trata-se de uma pesquisa não experimental e descritiva com uma abordagem qualitativa e quantitativa, de caráter descritivo e participativo, com o objetivo de considerar as respostas dos docentes da Escola Estadual Ministro Adauto Lúcio Cardoso, na cidade de Curvelo/MG.

Segundo Sampieri, Collado e Lúcio (2013) "a meta da pesquisa mista não é substituir a pesquisa quantitativa nem a pesquisa qualitativa, mas utilizar os pontos fortes de ambos os tipos, combinando-os".

O estudo utilizou o enfoque quantitativo. A amostra foi probabilística do tipo aleatório simples. Segundo Hernandez-Sampieri et al (2006), nesse tipo de amostragem, todos os elementos da população têm a mesma probabilidade de ser escolhido como elemento da amostra.

Os dados foram colhidos através de um questionário estruturado fechado aplicado aos professores da escola para a sondagem da realidade observada. Foram identificados e analisados aspectos relacionados à idade, carga horária de trabalho, 
motivos de ausência no trabalho, uso de medicamentos, consumo de bebidas, ajustamento de função com laudo, problemas de saúde que levou ao afastamento laboral, as circunstâncias que podem influenciar a saúde e as características do burnout.

Todo fenômeno estudado necessita seguir uma ordem determinada de passos, regras ou procedimentos que possibilitam na sua investigação a captação dos movimentos desse fenômeno, seu desenvolvimento e suas múltiplas contradições, afirma Bell (2008).

A população é formada por 56 professores de diversas disciplinas, com idade entre 26 a $4 \mathrm{I}$ anos, 03 gestores e 02 coordenadores pedagógicos. A amostra compreende a $52 \%$ dos professores, $67 \%$ da equipe gestora e $50 \%$ da equipe pedagógica. Ela está composta de 29 professores e 02 gestores e or coordenador pedagógico de uma única escola.

\section{RESULTADOS E DISCUSSÕES}

O tratamento dos dados foi feito com o uso de técnica de análise de conteúdo, onde, consiste na transformação dos dados coletados em conclusões, e/ou lições úteis e credíveis. "É, particularmente, utilizada para estudar material de tipo qualitativo" (Richardson, 1999, p.224). Assim, a análise dos dados se deu a partir da sondagem na literatura sobre o tema e após análise das respostas de questionário respondido pelos professores.

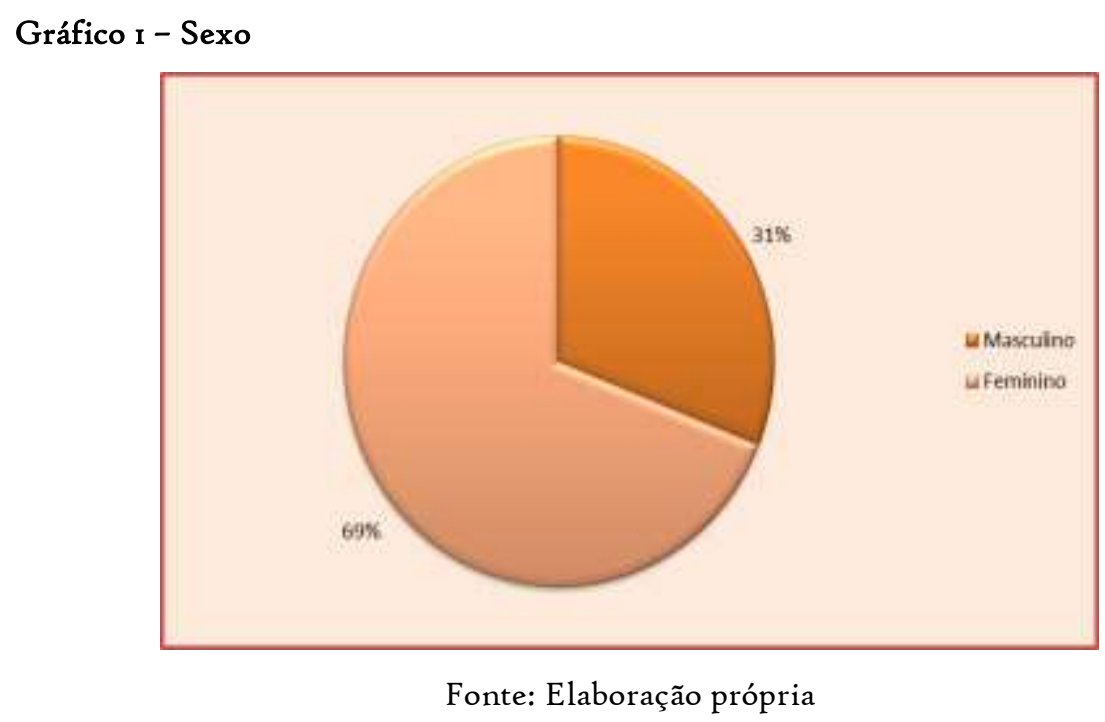


No gráfico I, observa-se que $31 \%$ dos entrevistados são do sexo masculino e 69\% são do sexo feminino. Estudos de Farber (199I) demonstraram que os professores do sexo masculino são mais vulneráveis que os do sexo feminino, o que levou à suposição de que mulheres são mais flexíveis e mais abertas para lidar com as várias pressões presentes na profissão de ensino.

No entanto, outros estudos apontam que as diferenças de gênero podem estabelecer incidências significativas no processo de adoecimento. Pesquisas que buscam entender a diferença na forma de adoecimento e a relação entre o burnout e o gênero vem se tornando frequente, porém seus resultados não são conclusivos, afirmam Schulz (2016) e Martins (2015).

As pesquisas apontam que as mulheres apresentam respostas mais elevadas na dimensão de exaustão emocional e os homens na dimensão despersonalização. Outros estudos, no entanto, não são encontrados diferenças significativas nos escores de burnout entre os gêneros, segundo Carlloto (20II).

Etzion (1987) associa as diferenças encontradas nos níveis do Burnout às questões tradicionais do processo de socialização e organização social, as quais se colocam diferenciadamente para homens e mulheres.

Gráfico 2 - Carga horária de trabalho

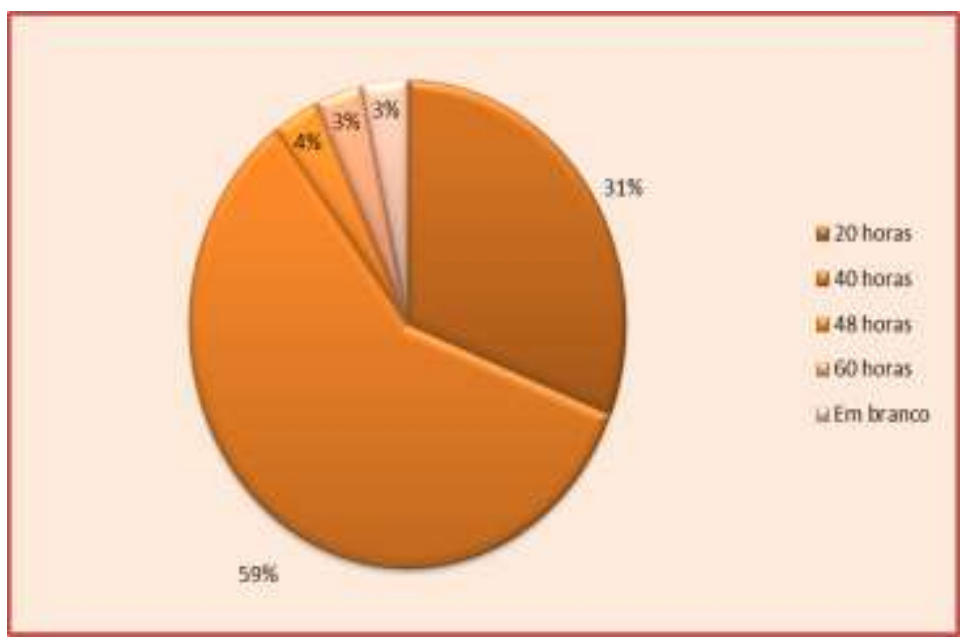

Fonte: Elaboração própria

No gráfico 2, permitiu contemplar que 59\% dos entrevistados têm 40 horas semanais de jornada de trabalho, $31 \%$ com 20 horas, $4 \%$ com 48 , 3\% 6o horas consecutivas e apenas $3 \%$ responderam em branco. 
A Constituição Brasileira de 1988 permite ao professor o acúmulo de carga horária num limite de até 64 horas semanais. São comuns a muitos professores brasileiros a sobrecarga de trabalho em sala de aulas por semana, pegando cerca de 20 horas/aula no município, outras 20 horas/aula no Estado e ainda outras 20 horas/aula na rede privada. A relação indivíduo e trabalho, assim como suas consequências, tem sido foco, cada vez mais, de estudos, devido a uma maior exigência do trabalhador.

Segundo Vieira (2010), queixas como excesso de trabalho e falta de tempo com a família tem sido recorrente entre os professores.

Assim, a carga horária de trabalho tem sido apontada como um importante fator estressor por esses profissionais. Portanto, há uma tendência nos professores a apresentarem características que favorecerá ao seu afastamento, como: depressão, desgaste, estresse - elementos característicos da conceituação da Síndrome de Burnout, como aponta (Codo, 2002, p. 240-242).

\section{Gráfico 3 - Tempo de docência}

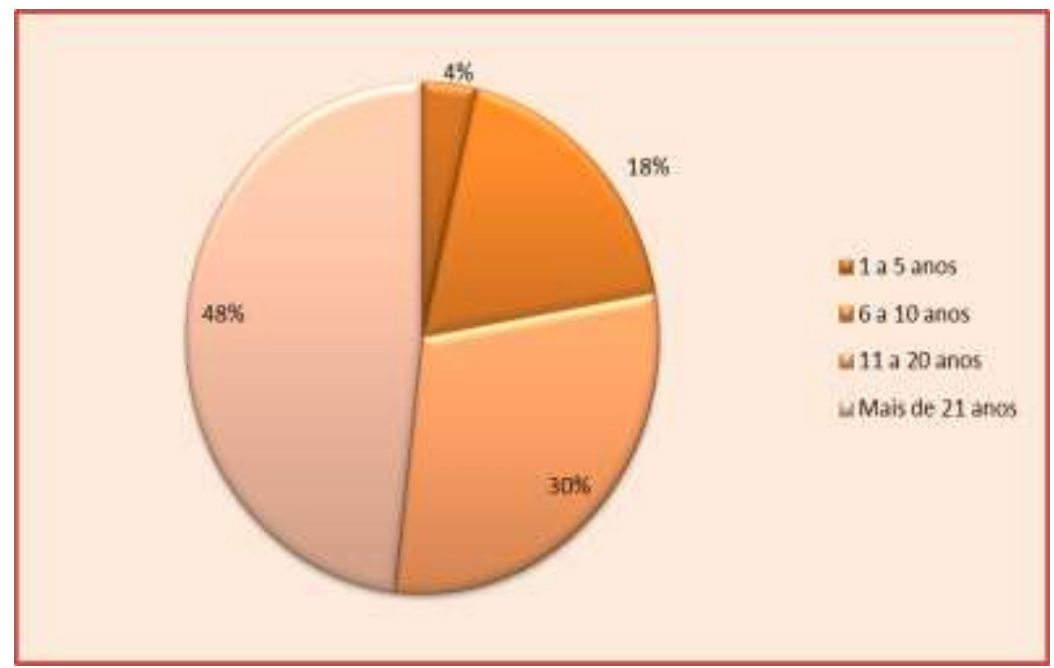

Fonte: Elaboração própria

No gráfico 3, apurou-se $48 \%$ dos entrevistados tem mais de 2I anos de docência, 30\% II a 20 anos, I8\% têm entre 6 a Io anos e 4\% são iniciantes na profissão docente. Carlotto (2002), afirma que em estudo realizado por Friedman (I99I) foi identificado que, os níveis de Burnout eram menores em professores com mais tempo de experiência.

Para Schwab e Iwanicki (1982) e Woods (1999), o nível de ensino em que o professor atua é mais relevante que os anos de prática, para eles professores de ensino 
fundamental e médio apresentavam mais atitudes negativas em relação aos alunos do que professores do ensino infantil

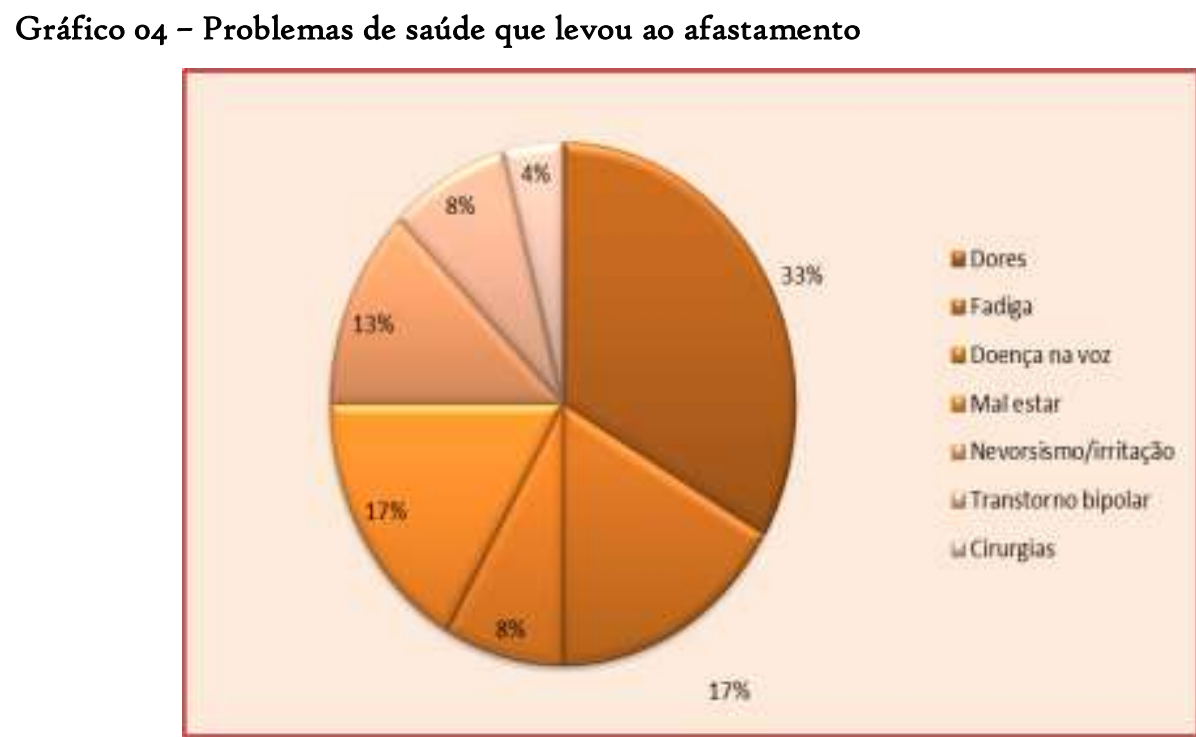

Fonte: Elaboração própria

No gráfico 04 , buscou-se saber se os entrevistados tiveram problemas de saúde que os levaram a licenciar-se do trabalho, nos últimos doze meses. 33\% relatam que dores, $17 \%$ atribuem as fadigas, $17 \%$ a mal-estar, $13 \%$ ao nervosismo e ou irritação, $8 \%$ a transtornos bipolar, 8\% doença na voz e 4\% a cirurgias. Freudenberger (1974), afirma que o Burnout é resultado de esgotamento, decepção e perda de interesse pela atividade de trabalho que surge nas profissões que trabalham em contato direto com pessoas em prestação de serviço como consequência desse contato diário no seu trabalho.

Gráfico os - Circunstâncias podem influenciar sua saúde

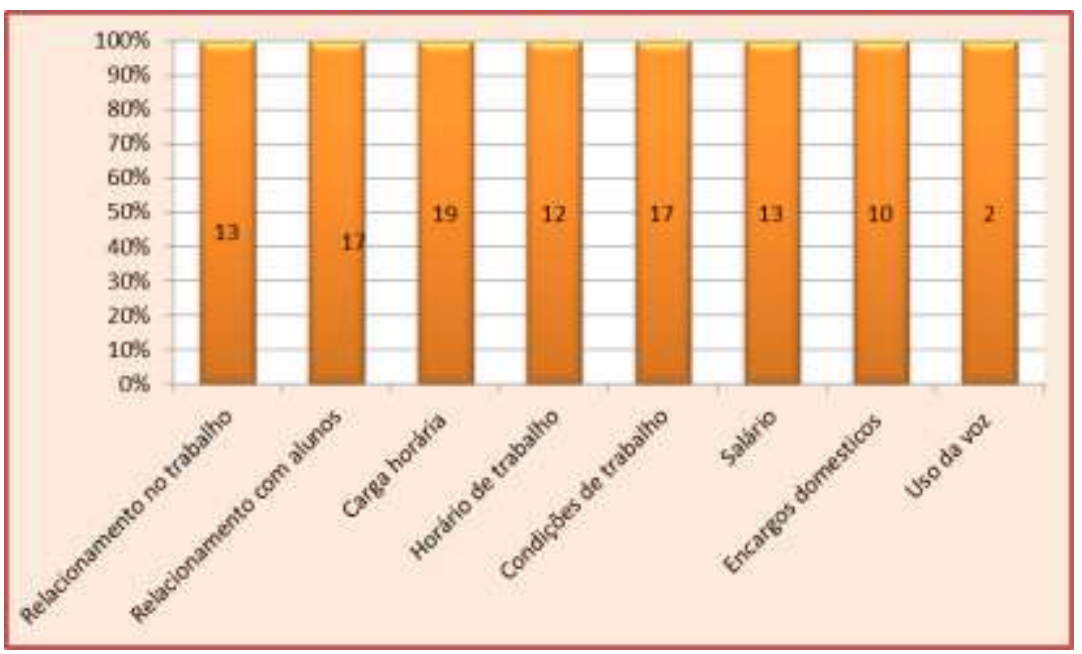

Fonte: Elaboração própria 
No gráfico 05, o objetivo foi saber as circunstâncias podem influenciar a saúde dos entrevistados. Em média 50\% dos entrevistados afirmaram que a carga horária pode influenciar a saúde docente, seguido das condições de trabalho, relacionamento com os alunos, com o trabalho, salário e demais fatores. Esteve (2009) considera que, diante da pressão de diversas fontes de tensão presentes no ensino, os professores põem em jogo diversos mecanismos de defesa (inibição, rotina, absenteísmo, etc.). Estes mecanismos baixam a qualidade da educação, mas servem para aliviar a tensão à qual o professor se encontra submetidos.

\section{Gráfico o6 - Características do Burnout}

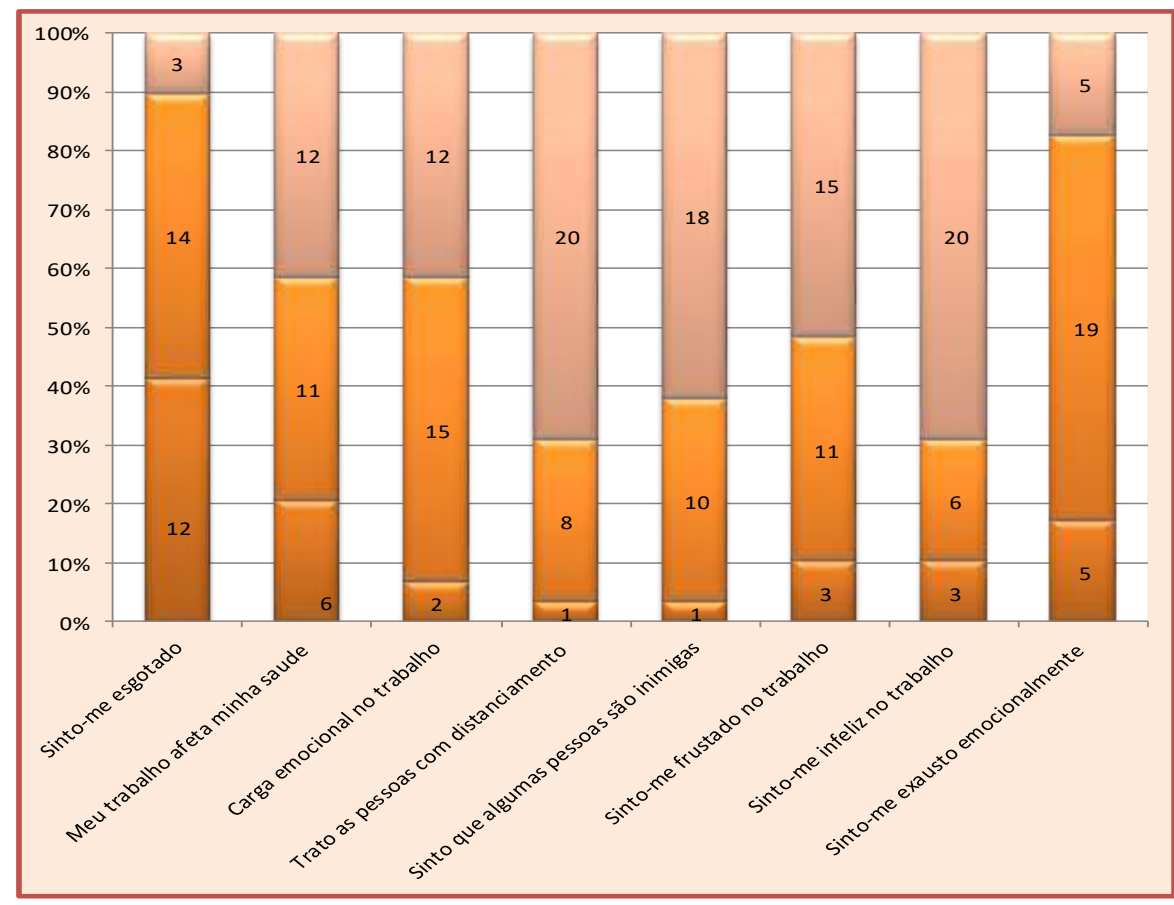

Fonte: Elaboração própria

No gráfico o6, a intenção foi saber dos entrevistados se eles apresentam características ao Burnout. A maior incidência recai sobre a exaustão, o esgotamento, carga emocional, seguido de frustação e insatisfação no trabalho.

Ser professor é uma das profissões mais estressantes na atualidade. Geralmente as jornadas de trabalho dos professores são longas, com raras pausas de descanso e/ou refeições breves e em lugares desconfortáveis. O ritmo intenso e variável, com início muito cedo pela manhã, podendo ser estendido até à noite em função de dupla ou tripla jornada de trabalho. No corre-corre os horários são desrespeitados, perdem-se horas de sono alimenta-se mal, e não há tempo para o lazer, afirma Tavares (2007) 
A presente pesquisa mostrou que a realização de atividades em diferentes escolas é uma realidade encontrada entre os profissionais que participaram deste estudo. A partir desse dado e somado às afirmações já apresentadas no decorrer deste texto, pode-se inferir que a carga horária excessiva de trabalho contribui para o desgaste físico e mental dos professores, além de induzi-los ao uso de medicações, absenteísmo e ausência ao trabalho, o que, são características da Síndrome de Burnout.

\section{CONSIDERAÇÕES FINAIS}

Os resultados encontrados, a partir da análise das respostas ao questionário, revelaram que os professores que participaram da pesquisa apresentaram uma sintomatologia geral de estresse, o que coincide com os estudos realizados por outros pesquisadores. Além disso, verificou-se que a sintomatologia psicológica se mostrou significativa para a exaustão emocional e a pouca realização pessoal no trabalho.

Observou-se também que as variáveis sexo, idade e filhos, indicadas como moduladoras em casos de estresse e Burnout, não apresentaram diferenças significativas. No entanto, encontrou-se relação positiva entre a jornada semanal de trabalho e a exaustão emocional, indicando que quanto maior a carga horária semanal dos professores, maior o esgotamento sentido por eles.

Em relação ao trabalho docente, especificamente, vários autores apontaram uma série de fatores que podem ser agentes estressores, como falta de reconhecimento e de respeito por falta dos alunos, das famílias, da sociedade, dos gestores e governantes, da sociedade, a falta de remuneração adequada, a sobrecarga de trabalho, o conflito de papéis, a baixa participação na gestão e planejamento do trabalho, a exigência de "dar conta" de toda a diversidade da sala de aula, o número excessivo de alunos por sala, dentre outros.

Os resultados da pesquisa demonstraram que os professores da rede estadual de ensino vêm apresentando características de um processo de Burnout, traduzindo a necessidade de instrumentá-los para saberem lidar melhor com os estressores comuns do seu dia-a-dia profissional, bem como verificar alternativas para tornar o ambiente e as relações laborais menos nocivas. 
Em relação às hipóteses levantadas, não foi possível comprovar a relação da Síndrome de Burnout com os casos de professores em Ajustamento Funcional. Porém, foi possível verificar um maior nível de esgotamento emocional, pouca realização pessoal no trabalho e sensação de ineficácia, características dessa síndrome, apareceram na maioria das respostas dos professores que responderam ao questionário. Esse fato pode corroborar para que a hipótese da relação entre os casos de ajustamento funcionais e os afastamentos saúde sejam decorrentes de fatores do Burnout.

Contudo, especificamente à escola, foco deste estudo, não foram encontrados registros com o diagnóstico de Síndrome de Burnout entre os professores na cidade de Curvelo. Os órgãos responsáveis pelos registros das licenças médicas não possuem um banco de dados com as causas mais comuns de afastamentos de docentes.

\section{REFERÊNCIAS}

BRASIL. Decreto $n^{0}$ 3.048, de o6 mai. 1999. Instituto Nacional de Seguro Social. Aprova o Regulamento da Previdência Social e dá outras providências. Diário Oficial da União, 7 mai. 1999. Republicado em 12 mai. 1999. Disponível em: 〈http://www3. dataprev.gov.br/sislex/paginas/23/1999/3048.htm >. Acesso em: I9 mar. 2018.

BELL, Judith. (2008). Como realizar um projeto de investigação: um guia para a pesquisa em Ciências sociais e da Educação. Barcelona: Ediciones CEAC, S.A.

Carlotto, Mary Sandra (2012). A Síndrome de Burnout e o trabalho docente. Psicologia em Esudos, Maringá, v. 7, n I, p. 21-29, jan/jun. Disponível em 〈http://www.scielo.br/pdf/\%oD/pe/v7ni/v7niao3.pdf〉 acessos em o7 fev 2018.

DIAS, F. M.; Santos, J. F. C.; Abelha, L.; Lovisi, G. M. (2016). O estresse ocupacional e a síndorme do esgotamento profissional (Burnout) em trabalhadores $\mathrm{da}$ industria do petróleo: uma revisão sistemática. Disponível em: < http://www.scielo.br/pdf/rbso/v4I/2317-6369-rbso-4I-eII.pdf> Acesso em: i4 fev 2018.

ESTEVE, J. M. (2009). O mal-estar docente: a sala de aula e a saúde dos professores. São Paulo: EDUSC.

ETZION, D. (1987). Burning out in management: a comparison of woman and men in matched organizational positions. Israel Social Science Research, 5, I\&2, I47-163.

FARBER, B. A. (199I) Inconsequentiality - The key to understanding teacher Burnout. Em Vanderbergue, R. \& Huberman, M. A. (Eds.), Understanding and preventing 
teacher Burnout: a source book of international practice and research (pp.159- 165). Cambridge: Cambridge University Press.

FRANÇA, H. H. (2007). A Síndrome de "Burnout". Revista Brasileira de Medicina, 44, 8, 197-199. Rio de Janeiro.

Freudenberger, H. J. (1974). Staff Burnout. Journal of Social Issues, 30, 159-165.

Jbelli, Chafic (2008). Superando o desânimo: antes que ele supere você. Rio de Janeiro: Nobel.

MARTINS, Sérgio Pinto (2015). Assédio Moral no Trabalho. Rio de Janeiro, Saraiva.

Maslach, C.; Jackson, S. E. (1981). The measurement of experienced Burnout. Journal of Occupational Behavior, 2, 99-I13.

Menegol, Alessandra. A Síndrome de Burnout como doença ocupacional e a concessão do benefício (B9I) pelo Instituto Nacional do Seguro Social (INSS).(2017). Disponível em: <https://jus.com.br/artigos/59240/a-sindrome-de-Burnout-como-doencaocupacional-e-a-concessao-do-beneficio-b9i-pelo-instituto-nacional-do-seguro-socialinss> Acesso em: 02 abr 2018

SCHAWB, R.L. \& Iwanicki, E.F. (1982). Perceived role conflict, role ambiguity, and teacher Burnout. Educational administration Quarterly, i8, 6o-74.

SCHULZ, S. Charles. Esquizofrenia. Disponível em: <https://www.msdmanuals.com/pt-br/casa/dist\%C $3 \%$ BArbios-de-sa\%C3\%BAdemental/esquizofrenia-e-transtorno-delirante/esquizofrenia> Acesso em: 09 abr 2018

VARELLA, Drauzio. Sindrome de Burnout. (2013). Disponível em: 〈http://drauziovarella.com.br/letras/b/sindrome-de-Burnout> Acesso em: o8 mar. 2018

VIEIRA I, Jardim SR. (2010). Burnout e reações de estresse. In: Glina, D. M. R.; Rocha, L. E. Saúde mental no trabalho: da teoria à prática. São Paulo: Roca; pp.269-76.

VIEIRA, Isabela; Ramos, Andréia; Martins, Dulcéa; Bucasio, Erika; Pereira, Ana Maria Tereza Benevides; Figueira, Ivan; Jardim, Sílvia (2006). Burnout na clínica psiquiátrica: relato de um caso. In: Revista de Psiquiatria do Rio Grande do Sul vol.28 no3 Porto Alegre Set./Dez. 2006. Disponível em:<revista@aprs.org.br>Acesso em: 27 jan 2018

WOODS, P. (2009). Intensification and stress in teaching. Em Vanderbergue, R. \& HUBERMAN, M. A. (Eds.) Understanding and preventing teacher Burnout: a source book of international practice and research (pp.115-138). Cambridge: Cambridge University Pres. 